\title{
Crystal Structure and Stereochemistry Study of 2-Substituted Benzoxazole Derivatives
}

\author{
Ahmed F. Mabied, ${ }^{1}$ Elsayed M. Shalaby, ${ }^{1}$ Hamdia A. Zayed, ${ }^{2}$ Esmat El-Kholy, ${ }^{1}$ \\ Ibrahim S. A. Farag, ${ }^{1}$ and Naima A. Ahmed ${ }^{1}$ \\ ${ }^{1}$ Crystallography Laboratory, Physics Division, National Research Center, Dokki, Giza 12622, Egypt \\ ${ }^{2}$ Physics Department, Women's College, Ain Shams University, Cairo 11757, Egypt
}

Correspondence should be addressed to Ahmed F. Mabied; mabied@xrdlab-nrc-eg.org

Received 10 January 2014; Accepted 5 March 2014; Published 13 May 2014

Academic Editors: N. Farfan, C. W. Lehmann, and T. Polonski

Copyright (C) 2014 Ahmed F. Mabied et al. This is an open access article distributed under the Creative Commons Attribution License, which permits unrestricted use, distribution, and reproduction in any medium, provided the original work is properly cited.

\begin{abstract}
The structure of 2-[(4-chlorophenylazo) cyanomethyl] benzoxazole, $\mathrm{C}_{15} \mathrm{H}_{9} \mathrm{ClN}_{4} \mathrm{O}(\mathrm{I})$, has triclinic $(P \overline{1})$ symmetry. The structure displays $\mathrm{N}-\mathrm{H} \cdots \mathrm{N}$ hydrogen bonding. The structure of 2-[(arylidene) cyanomethyl] benzoxazoles, $\mathrm{C}_{17} \mathrm{H}_{10} \mathrm{~N}_{2} \mathrm{O}_{3}$ (II), has triclinic $(P \overline{1})$ symmetry. The structure displays $\mathrm{C}-\mathrm{H} \cdots \mathrm{N}, \mathrm{C}-\mathrm{H} \cdots \mathrm{C}$ hydrogen bonding. In (I), the chlorophenyl and benzoxazole groups adopt a trans configuration with respect to the central cyanomethyle hydrazone moiety. Compound (II) crystallized with two molecules in the asymmetric unit shows cisoid conformation between cyano group and benzoxazole nitrogen, contrary to (I). In (II) the benzodioxole has an envelope conformation (the $\mathrm{Cl}$ atom is the flap atom). The molecular geometry obtained using molecular mechanics (MM) calculations has been discussed along with the results of single crystal analysis.
\end{abstract}

\section{Introduction}

Benzoxazole derivatives are one of the most important bioactive heterocyclic organic compounds in pharmaceutical chemistry. They have been used as a starting material for synthesis of bioactive structures of pharmaceutical drugs, such as the antibiotic Calcimycin that includes a 2-substituted benzoxazole ring in its molecular structure $[1,2]$. Previous studies revealed that substituted benzoxazoles possess diverse chemotherapeutic activities including antibiotic, antimicrobial, antiviral, topoisomerase inhibitors, and antitumor activities [3-6]. Benzoxazoles possess the structural isosteres of natural nucleotides (such as adenine and guanine) which allows them to interact easily with the biopolymers of living systems [7]. Also benzoxazole derivatives have been entered in the synthesis of new classes of antibacterial drug, which has showed activity against bacterial infections [8]. Benzoxazoles are also widely used in industry, such as a photostable highly efficient UV dyes, a dopant in organic light-emitting diodes, chromophores, and chemosensors $[9,10]$.
It was reported that knowing the crystal structure and conformation of 2-substituted benzoxazole derivatives supports important information for predicting their mode of orientation on the receptor [3]. Then, more bioactive drugs in the pharmaceutical industry could be designed.

In view of the aforementioned literature survey and to support the pharmaceutical and organic chemistry scientists with structural aspects that may be of value in designing new derivatives and potent drugs, we present the geometrical, stereochemical features of two bioactive 2-substituted benzoxazole derivatives comparing their structures with each other and related structures, using X-ray single crystal analysis and molecular mechanics (MM) calculations. The chosen derivatives are 2-[(4-chlorophenylazo) cyanomethyl] benzoxazole, $\mathrm{C}_{15} \mathrm{H}_{9} \mathrm{ClN}_{4} \mathrm{O}$ (I) and 2-[(arylidene) cyanomethyl] benzoxazole, $\mathrm{C}_{17} \mathrm{H}_{10} \mathrm{~N}_{2} \mathrm{O}_{3}$ (II).

\section{Materials and Methods}

2.1. Synthesis. The target compounds have been prepared according to the reported procedure [3] (Scheme 1). They 


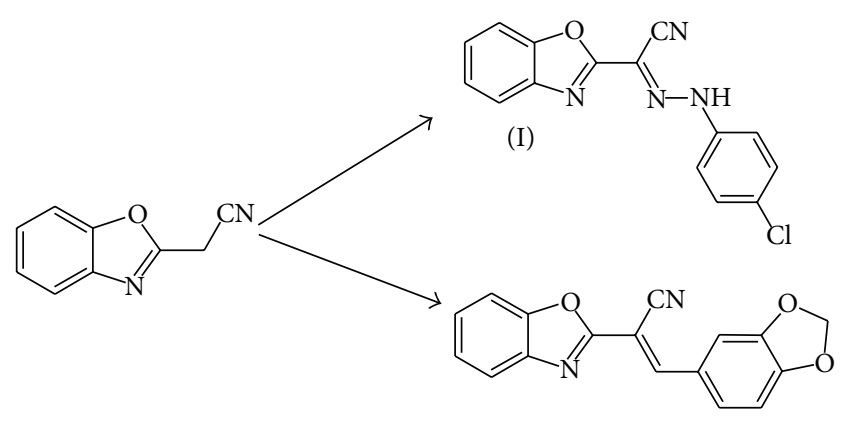

(II)

Scheme 1: Chemical diagram of the target compounds.

were obtained mainly from diazocoupling of 2-cyanomethylbenzoxazole with appropriate diazonium acetate to attach hydrazone, cyano, or thiazole, which reported as the function groups of the bioactivity. Melting points were determined in open-glass capillaries on a Gallenkamp melting point apparatus and are uncorrected. The IR spectra were recorded using $\mathrm{KBr}$ discs on a Perkin-Elmer 1430 spectrophotometer.

Compound (I). An ice-cooled solution of the diazonium acetate [prepared by the addition of solution of sodium nitrite $(1 \mathrm{~g}, 15 \mathrm{mmole})$ in water $(5 \mathrm{~mL})$ to the required arylamine $(10 \mathrm{mmole})$ in acetic acid $(10 \mathrm{~mL})$ ] was added dropwise with stirring to a solution of 2-cyanomethylbenzoxazole $(1.58 \mathrm{~g}$, $10 \mathrm{mmole}$ ) in acetic acid (5 mL). Stirring was maintained for 30 minutes after which water was added and the precipitated product was filtered, washed with water, dried, and crystallized by slow evaporation from ethanol. IR of compound (I) $\left(v \mathrm{~cm}^{-1}\right)$ is as follows: $3171-3066(\mathrm{NH}) ; 2226-2223(\mathrm{C} \equiv \mathrm{N})$; 1611-1599, 1551-1550, 1502-1481 ( $\mathrm{C}=\mathrm{N}, \mathrm{NH}$ bending, $\mathrm{C}=\mathrm{C})$; 1278-1266, 1097-1087 (C-O-C).

Compound (II). Triethylamine (5 drops) and the aldehyde (4 mmole) were added to a stirred solution of 2-cyanomethylbenzoxazole $(0.63 \mathrm{~g}, 4 \mathrm{mmole})$ in absolute ethanol $(10 \mathrm{~mL})$. The reaction mixture was stirred at room temperature for 3 hours during which yellow crystals separated out. The crystalline product was filtered, washed with ethanol, dried, and crystallized by evaporation from dioxane solvent. IR of compound (II) $\left(v \mathrm{~cm}^{-1}\right)$ is as follows: $2230-2223(\mathrm{C} \equiv \mathrm{N})$; 1588-1574, 1513-1502 (C=N, C=C); 1271-1240, 1180-1150, 1040-1022 (C-O-C).

2.2. X-Ray Single Crystal Measurements. Crystals were selected and checked for imperfections such as cracks, bubbles, twining, or voids and mounted onto thin glass fibers and glued with epoxy glue. X-ray diffraction data were collected at room temperature on an Enraf-Nonius 590 Kappa CCD single crystal diffractometer with graphite monochromated Mo-K $\alpha(\lambda=0.71073 \AA)$ radiation, at National Research Center of Egypt [11, 12]. Crystal data, data collection, and structure refinement details are summarized in Table 1. The relatively large ratio of minimum to maximum corrections applied in the multiscan process $(1 \mathrm{nnn})$ reflects changes in the illuminated volume of the crystal. Changes in illuminated

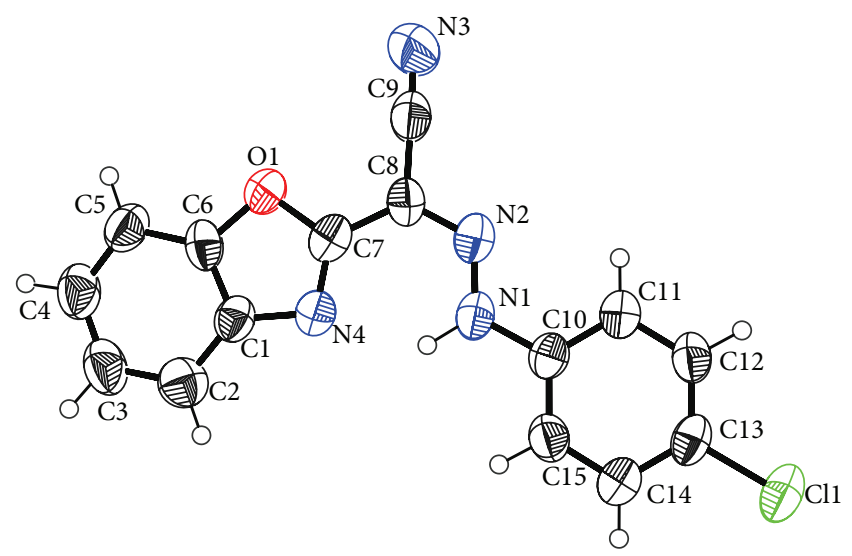

FIGURE 1: The 50\% probability displacement ellipsoids representation of compound (I).

volume were kept to a minimum and were taken into account [13] by the multiscan interframe scaling [14].

The crystal structures were solved using Superflip [15], which revealed the positions of all nonhydrogen atoms and refined by the full matrix least squares refinement based on $\mathrm{F}^{2}$ using CRYSTALS package [16]. The anisotropic displacement parameters of all nonhydrogen atoms were refined, and then the hydrogen atoms were all located in a difference map, but those attached to carbon atoms were repositioned geometrically. The $\mathrm{H}$ atoms were initially refined with soft restraints on the bond lengths and angles to regularise their geometry $(\mathrm{C}-\mathrm{H}$ in the range $0.93-0.98, \mathrm{~N}-\mathrm{H}$ in the range 0.86-0.89 $\mathrm{N}-\mathrm{H}$ to $0.86 \mathrm{O}-\mathrm{H}=0.82 \AA$ ) and $\mathrm{U}_{\text {iso }}(\mathrm{H})$ (in the range 1.21.5 times $\mathrm{U}_{\text {eq }}$ of the parent atom). Then, the positions were refined with riding mode (95 $\AA$ ) [17]. The molecular graphics were prepared using Diamond [18] program.

The crystal data is listed in Table 1 . The full crystallographic information can be obtained free of charge using deposit numbers CCDC 675940 and CCDC 692455 for (I) and (II), respectively, via http://www.ccdc.cam.ac.uk/conts/ retrieving.html or from the Cambridge Crystallographic Data Centre, Cambridge, UK.

2.3. Molecular Mechanics Computations. Molecular mechanics in vacuo computations were carried out using HyperChem package [19]. The molecular mechanics $(\mathrm{MM}+)$ force field was used as it is developed principally for organic molecules [20-22]. The process of energy minimization was carried out by Steepest Descents method. The conformational energy of the molecule was calculated. The lowest energy conformation is shown and compared to the crystal structures.

\section{Results and Discussions}

3.1. Crystal Structure Description. Structures of compounds (I) and (II) consist mainly of benzoxazole connected with different chemical moieties at C7 (Figures 1 and 2). Two independent molecules in the asymmetric unit cell have been found in the second compound, IIa and IIb. 
TABLE 1: Crystal data of the studied compounds.

\begin{tabular}{|c|c|c|}
\hline & (I) & (II) \\
\hline \multicolumn{3}{|c|}{ Crystal data } \\
\hline Chemical formula & $\mathrm{C}_{15} \mathrm{H}_{9} \mathrm{ClN}_{4} \mathrm{O}$ & $\mathrm{C}_{17} \mathrm{H}_{10} \mathrm{~N}_{2} \mathrm{O}_{3}$ \\
\hline$M_{r}$ & 296.72 & 290.28 \\
\hline Crystal system, space group & Triclinic, $P \overline{1}$ & Triclinic, $P \overline{1}$ \\
\hline Temperature (K) & 298 & 298 \\
\hline$a, b, c(\AA)$ & $7.5050(7), 7.4836(10), 13.4301(17)$ & 7.4919 (5), $13.0828(9), 14.1914(14)$ \\
\hline$\alpha, \beta, \gamma\left({ }^{\circ}\right)$ & $106.488(6), 90.485(7), 102.759(8)$ & $94.355(3), 101.180(3), 102.504(6)$ \\
\hline$V\left(\AA^{3}\right)$ & $703.37(15)$ & $1322.07(19)$ \\
\hline$Z$ & 2 & 4 \\
\hline Radiation type & Mo K $\alpha$ & Mo K $\alpha$ \\
\hline$\mu\left(\mathrm{mm}^{-1}\right)$ & 0.28 & 0.10 \\
\hline Crystal size (mm) & $0.12 \times 0.10 \times 0.09$ & $0.12 \times 0.11 \times 0.08$ \\
\hline \multicolumn{3}{|c|}{ Data collection } \\
\hline Absorption correction & Multiscan & Multiscan \\
\hline$T_{\min }, T_{\max }$ & $0.97,0.98$ & $0.99,0.99$ \\
\hline $\begin{array}{l}\text { Number of measured, } \\
\text { independent and observed } \\
{[I>2.0 \sigma(I)] \text { reflections }}\end{array}$ & $4166,3007,1543$ & $7240,4861,2163$ \\
\hline$R_{\text {int }}$ & 0.031 & 0.084 \\
\hline$(\sin \theta / \lambda)_{\max }\left(\AA^{-1}\right)$ & 0.655 & 0.617 \\
\hline \multicolumn{3}{|c|}{ Refinement } \\
\hline$R\left[F^{2}>2 \sigma\left(F^{2}\right)\right], w R\left(F^{2}\right), S$ & $0.071,0.070,1.13$ & $0.089,0.155,0.97$ \\
\hline $\begin{array}{l}\text { Number of reflections, } \\
\text { parameters, and restraints }\end{array}$ & $1309,64,0$ & $1738,133,0$ \\
\hline$\Delta \rho_{\max }, \Delta \rho_{\min }\left(e \AA^{-3}\right)$ & $0.25,-0.26$ & $0.33,-0.25$ \\
\hline
\end{tabular}

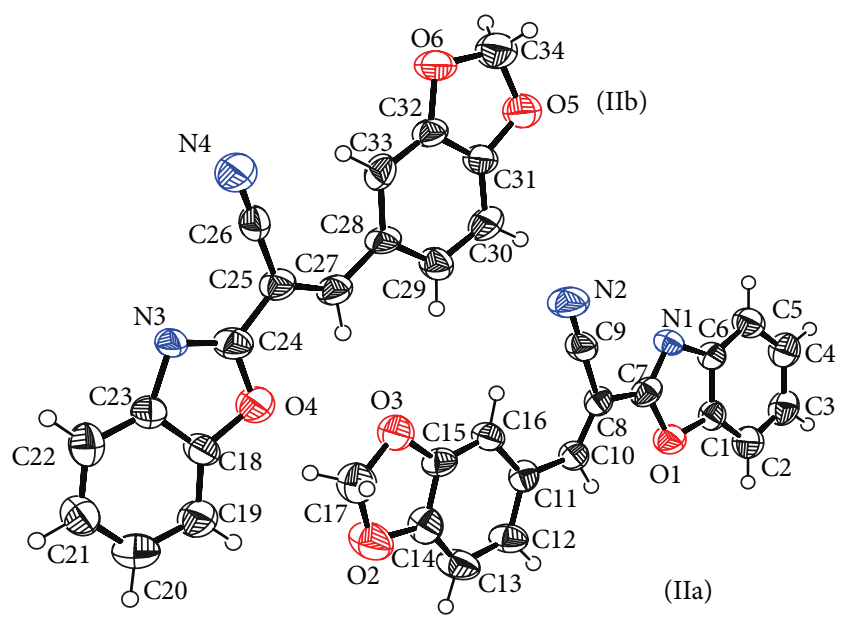

Figure 2: The $50 \%$ probability displacement ellipsoids representation of compound (II).

Benzoxazole is almost planar, where the maximum deviation from the mean plane corresponds to the atom $\mathrm{C} 2,-0.013$ (3) $\AA$ in (I) and the atoms C6, 0.008 (6) $\AA$ and O4, -0.012 (4) $\AA$, in (IIa) and (IIb), respectively. This is comparable with the reported structures which have the same moiety, such as 2-(4-aminophenyl)-1, 3-benzoxazole [23], 2-amino5-chloro-1, 3-benzoxazole [24], and 5-(2-chlorobenzoyl)1,3-benzoxazol-2(3H)-one [25], also the related structures reported in [26]. The phenyl ring in (I) has planer configuration where the maximum deviation corresponds to the atom $\mathrm{C12}, 0.010$ (3) A. Benzoxazole group and the phenyl ring adopt a trans configuration with respect to the central cyanomethyle hydrazone moiety, with dihedral angle between the two mean ring planes $180^{\circ}$.

In compound (II), the benzoxazole group is linked to benzodioxol via acrylonitrile moiety. Planar configuration of benzodioxole moiety in (IIb) is confirmed by the deviation of the benzodioxole atoms from their best plane, with maximum deviation at O6, -0.026 (4) $\AA$. However, in (IIa), the dioxole ring adopts the envelope conformation with $\mathrm{C} 17$ deviating from the plane defined by the rest of the atoms of the ring (O2- C17) by -0.069 (7) A. The puckering parameters [27] of this ring are $Q=0.109$ (6) $\AA$ and $\varphi=329(3)^{\circ}$.

Conformational investigation of the structures reveals that there is cisoid conformation between the cyano group and benzoxazole nitrogen in compound (II) (Figure 2), which in agreement with the reported cisoid conformation of 2-[(3-hydroxy-4-methoxybenzylidene)-cyanomethyl]benzoxazole [3]. In contrary in compound (I) (Figure 1) the cyano group and benzoxazole nitrogen shows transoid conformation, as reported before such information would 


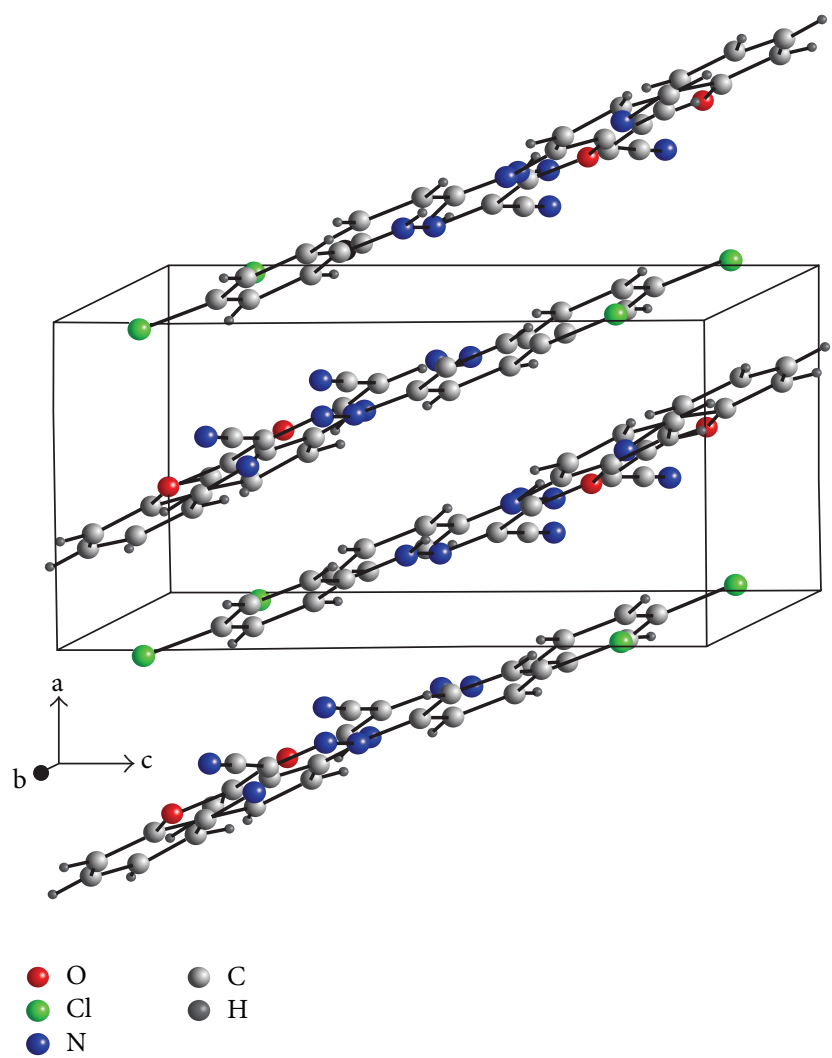

FIGURE 3: The molecular packing of (I).

TABLE 2: Hydrogen-bond geometry $\left(\AA,^{\circ}\right)$ for (I).

\begin{tabular}{lcccc}
\hline$D-\mathrm{H} \cdots A$ & $D-\mathrm{H}$ & $\mathrm{H} \cdots A$ & $D \cdots A$ & $D-\mathrm{H} \cdots A$ \\
\hline $\mathrm{N} 1-\mathrm{H} 11 \cdots \mathrm{N} 4$ & 0.950 & 1.975 & $2.710(4)$ & 133 \\
\hline
\end{tabular}

TABLe 3: Hydrogen-bond geometry $\left(\AA{ }^{\circ}\right)$ for (II).

\begin{tabular}{lcccc}
\hline$D-\mathrm{H} \cdots A$ & $D-\mathrm{H}$ & $\mathrm{H} \cdots A$ & $D \cdots A$ & $D-\mathrm{H} \cdots A$ \\
\hline $\mathrm{C} 13-\mathrm{H} 131 \cdots \mathrm{N} 4^{\mathrm{i}}$ & 0.950 & 2.519 & $3.431(8)$ & 161 \\
$\mathrm{C} 16-\mathrm{H} 161 \cdots \mathrm{N} 2$ & 0.950 & 2.600 & $3.450(8)$ & 149 \\
$\mathrm{C} 16-\mathrm{H} 161 \cdots \mathrm{C} 9$ & 0.950 & 2.433 & $3.063(8)$ & 124 \\
$\mathrm{C} 30-\mathrm{H} 301 \cdots \mathrm{N} 2$ & 0.950 & 2.574 & $3.464(8)$ & 156 \\
$\mathrm{C} 33-\mathrm{H} 331 \cdots \mathrm{C} 26$ & 0.950 & 2.426 & $3.052(8)$ & 123 \\
\hline
\end{tabular}

Symmetry code: ${ }^{\mathrm{i}} x-1, y-1, z$.

add an important way for predicting the geometry of the drug-receptor interaction [3].

The structures are stabilized by the intermolecular interactions and a network of hydrogen bond contacts conformed parallel layers, $\mathrm{N}-\mathrm{H} \cdots \mathrm{N}$ in compound (I), Table 2, and C$\mathrm{H} \cdots \mathrm{N}$ and $\mathrm{C}-\mathrm{H} \cdots \mathrm{C}$ in compound (II), Table 3 . The packing diagrams of the compounds are shown in Figures 3 and 4.

3.2. Molecular Mechanics Computations. The minimum energy structure obtained by molecular mechanics of the investigated compounds did not match well the crystal structures obtained experimentally, Figures 5 and 6 . However,

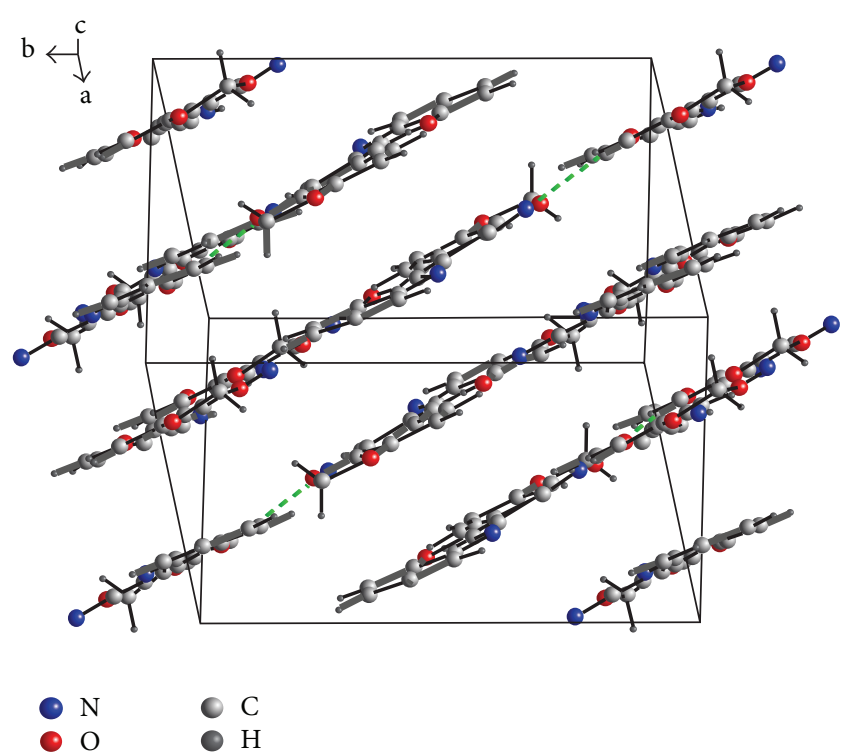

FIGURE 4: The molecular packing of (II) with the intermolecular interactions shown as dashed line.

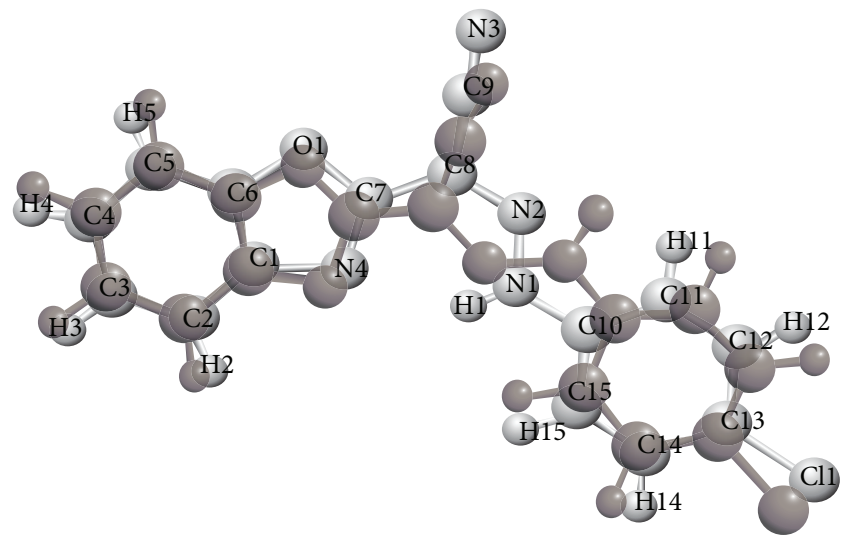

FIGURE 5: Superimposition view of the calculated structure (black) on the X-ray structure (gray) for the compound (I).

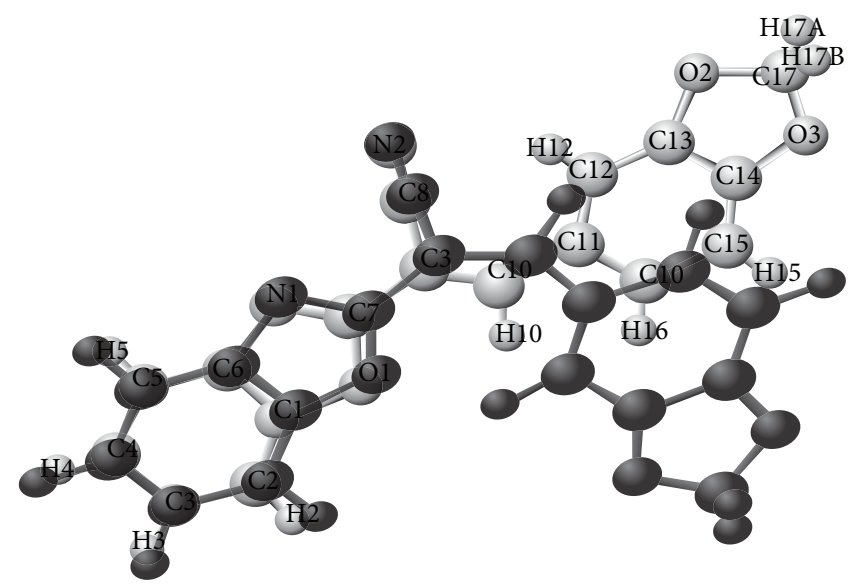

FIGURE 6: Superimposition view of the calculated structure (black) on the X-ray structure (gray) for the compound (II). 
TABLE 4: Selected geometrical values of molecular mechanics and experimentally obtained structures of compound (I).

\begin{tabular}{lccccc}
\hline Bond length $(\AA)$ & Exp. & MM & Bond angles $\left(^{\circ}\right)$ & Exp. & MM \\
\hline N1-N2 & $1.317(3)$ & 1.354 & C1-C2-C3 & $117.1(3)$ & 117.07 \\
N2-C8 & $1.307(4)$ & 1.3485 & C3-C4-C5 & $121.6(3)$ & $115.7(3)$ \\
C8-C9 & $1.434(4)$ & 1.31 & O1-C7-N4 & $115.8(3)$ \\
C1-C2 & $1.381(4)$ & 1.390 & Cl1-C13-C14 & $179.5(4)$ & 119.9 \\
C6-C1 & $1.387(4)$ & 1.384 & C6-O1-C7-C8 & 180 \\
Cl1-C13 & $1.737(3)$ & 1.726 & C10-N1-N2-C8 & $179.1(5)$ & $130(2)$ \\
C10-C11 & $1.375(4)$ & 1.398 & C7-C8-C9-N3 & $179.6(5)$ & 179.99 \\
C11-C12 & $1.395(4)$ & 1.398 & N2-N1-C10-C15 & $179.9(5)$ & 180 \\
C13-C12 & $1.369(5)$ & 1.396 & H1-N1-C10-C11 & $187.5(8)$ \\
C13-C14 & $1.389(5)$ & 1.396 & H1-N1-C10-C15 & $1.0(8)$ \\
N4-C1 & $1.400(4)$ & 1.348 & C10-N1-H1-N4 & $179.7(13)$ \\
N4-C7 & $1.294(4)$ & 1.358 & & 180 \\
\hline
\end{tabular}

TABLE 5: Selected geometrical values of molecular mechanics and experimentally obtained structures of compound (II).

\begin{tabular}{|c|c|c|c|c|c|}
\hline Bond length $(\AA)$ & Exp. & MM & Bond angles $\left({ }^{\circ}\right)$ & Exp. & MM \\
\hline N1-C6 & $1.403(5)$ & 1.348 & $\mathrm{C} 1-\mathrm{C} 6-\mathrm{C} 5$ & $120.7(4)$ & 121.59 \\
\hline $\mathrm{N} 1-\mathrm{C} 7$ & $1.279(5)$ & 1.363 & $\mathrm{C} 9-\mathrm{C} 8-\mathrm{C} 7$ & $112.1(4)$ & 112.90 \\
\hline C6-C5 & $1.366(5)$ & 1.390 & $\mathrm{C} 8-\mathrm{C} 10-\mathrm{C} 11$ & $131.3(4)$ & 221.59 \\
\hline $\mathrm{C} 6-\mathrm{C} 1$ & $1.378(5)$ & 1.381 & $\mathrm{C} 13-\mathrm{C} 14-\mathrm{C} 15$ & $123.1(5)$ & 122.58 \\
\hline $\mathrm{C} 1-\mathrm{C} 2$ & $1.372(6)$ & 1.390 & $\mathrm{O} 2-\mathrm{C} 17-\mathrm{O} 3$ & $107.6(3)$ & 105.35 \\
\hline C5-C4 & $1.373(6)$ & 1.399 & $\mathrm{C} 13-\mathrm{C} 12-\mathrm{C} 11$ & $117.6(4)$ & 116.18 \\
\hline $\mathrm{C} 4-\mathrm{C} 3$ & $1.395(6)$ & 1.403 & $\mathrm{C} 7-\mathrm{O} 1-\mathrm{C} 1-\mathrm{C} 2$ & $179.8(9)$ & 180 \\
\hline $\mathrm{N} 2-\mathrm{C} 9$ & $1.132(1)$ & 1.15 & $\mathrm{O} 1-\mathrm{C} 1-\mathrm{C} 2-\mathrm{C} 3$ & $179.8(11)$ & 180 \\
\hline $\mathrm{C} 9-\mathrm{C} 8$ & $1.423(6)$ & 1.321 & C7-N1-C6-C5 & $179.0(10)$ & 180 \\
\hline $\mathrm{C} 7-\mathrm{C} 8$ & $1.460(5)$ & 1.345 & N1-C7-C8-C9 & $4.2(6)$ & 0 \\
\hline $\mathrm{C} 11-\mathrm{C} 12$ & $1.419(5)$ & 1.417 & $\mathrm{C} 11-\mathrm{C} 10-\mathrm{C} 8-\mathrm{C} 7$ & $178.1(11)$ & 0 \\
\hline $\mathrm{C} 10-\mathrm{C} 11$ & $1.446(5)$ & 1.353 & $\mathrm{C} 13-\mathrm{C} 12-\mathrm{C} 11-\mathrm{C} 10$ & $-179.2(10)$ & 179.99 \\
\hline
\end{tabular}

trans configuration between benzoxazole group and the benzene ring with respect to the central cyanomethyle hydrazone moiety appears also in the theoretical structure. The global energy minimum conformations as calculated by molecular mechanics in vacuo in agreement with the above-mentioned crystallographically observed conformations, where cisoid conformation has noticed only in (II).

Tables 4 and 5 show selected geometrical values of experimentally obtained structure using X-ray (Exp.) and molecular mechanics (MM) for (I) and (II), respectively. The bonds of the benzoxazole ring obtained theoretically in (I) and (II) almost agree with those obtained experimentally with Xray diffraction. On the other hand, in (I) the deference is $180^{\circ}$ degree in N2-N1-C10-C15 and H11-N1-C10-C11 torsion angles. Also, there is considerable variation of C11-C10-C8C7 torsion angle in (II). It was found that benzodioxole ring has orientation in the experimental structure different from the orientation of the same group in the theoretical structure.

However, the energy of the experimental structures was higher than the energy of the structure obtained using molecular mechanics by the values $5.8 \mathrm{kcal} \cdot \mathrm{mol}^{-1}$ in compound (I) and $1.9 \mathrm{kcal} \cdot \mathrm{mol}^{-1}$ in compound (II). This variation may be due to the fact that the experimental structure of the investigated compounds in crystal conditions (i.e., the neighbouring molecules, hydrogen bonding, and other nonbonded interactions in the crystal lattice environment) is taken into account. This is in agreement with what was reported in the literature showing that the effects of hydrogen-bonding and van der Waals interactions in the crystal structure cause the molecules to adopt higher-energy conformations, which correspond to local minima in the molecular potential energy surface [28]. This result in consent with the reported notation, which states that the crystallographically observed molecular architecture is a local energy minimum in the absence of its crystal lattice environment [29].

\section{Conclusions}

Crystallographic and stereochemical study of 2substituted benzoxazole derivatives, 2-[(4-chlorophenylazo) cyanomethyl] benzoxazole and 2-[(arylidene) cyanomethyl] benzoxazole, has been introduced using X-ray single crystal and MM. The study has reported that the crystal structures of the two compounds have a triclinic $(P \overline{1})$ space group. The study showed in (II) that cisoid conformation between the cyano group and benzoxazole nitrogen and the benzodioxole 
has an envelope conformation. The features of the whole molecules obtained using MM do not match well those obtained by X-ray; however, the results have supported the conformation discussion.

\section{Conflict of Interests}

The authors declare that there is no conflict of interests regarding the publication of this paper.

\section{Acknowledgments}

This work is one of the seeds Professor Naima AbdelKader Ahmed (Crystallography Laboratory, NRC, Egypt) has planted, so the authors would like to offer a thank you to her kind soul. The authors thank the Pharmaceutical Chemistry Group, Faculty of Pharmacy, University of Alexandria, Egypt, for the great help.

\section{References}

[1] M. Prudhomme, J. Guyot, and G. Jeminet, "Semi-synthesis of A23187 (calcimycin) analogs. IV. Cation carrier properties in mitochondria of analogs with modified benzoxazole rings. Antimicrobial activity," The Journal of Antibiotics, vol. 39, no. 7, pp. 934-937, 1986.

[2] C. Youssef, H. B. Ammar, M. Belhouchet et al., "Syntheses of new benzoxazole derivatives," Journal of Heterocyclic Chemistry, vol. 48, no. 5, pp. 1126-1131, 2011.

[3] S. M. Rida, F. A. Ashour, S. A. M. El-Hawash, M. M. ElSemary, M. H. Badr, and M. A. Shalaby, "Synthesis of some novel benzoxazole derivatives as anticancer, anti-HIV-1 and antimicrobial agents," European Journal of Medicinal Chemistry, vol. 40, no. 9, pp. 949-959, 2005.

[4] J. Karolak-Wojciechowska, A. Mrozek, R. Czylkowski, B. Tekiner-Gulbas, E. Akı-Şener, and I. Yalçin, "Five-membered heterocycles. Part IV: impact of heteroatom on benzazole aromaticity," Journal of Molecular Structure, vol. 839, no. 1-3, pp. 125-131, 2007.

[5] A. O. Abdelhamid, V. B. Baghos, and M. M. A. Halim, "Synthesis and reactivity of N-[3-amino-4-(benzoxazol-2-yl)pyrazol-5-yl] phenylamine," Journal of Chemical Research, vol. 2007, no. 7, pp. 420-425, 2007.

[6] S. A. Shiba, A. K. El-Ziaty, N. K. El-Aasar, and H. A. AlSaman, "Uses of piperonal in the synthesis of novel prop-2enoyl amides, esters, heterocyclic systems and study of their antibacterial activities," Journal of Chemical Research, vol. 2008, no. 9, pp. 500-506, 2008.

[7] S. M. Sondhi, N. Singh, A. Kumar, O. Lozach, and L. Meijer, "Synthesis, anti-inflammatory, analgesic and kinase (CDK-1, CDK-5 and GSK-3) inhibition activity evaluation of benzimidazole/benzoxazole derivatives and some Schiff's bases," Bioorganic \& Medicinal Chemistry, vol. 14, no. 11, pp. 3758-3765, 2006.

[8] I. Yildiz-Oren, I. Yalcin, E. Aki-Sener, and N. Ucarturk, "Synthesis and structure-activity relationships of new antimicrobial active multisubstituted benzazole derivatives," European Journal of Medicinal Chemistry, vol. 39, no. 3, pp. 291-298, 2004.
[9] K. Guzow, D. Szmigiel, D. Wróblewski, M. Milewska, J. Karolczak, and W. Wiczk, "New fluorescent probes based on 3-(2benzoxazol-5-yl)alanine skeleton-synthesis and photophysical properties," Journal of Photochemistry and Photobiology A: Chemistry, vol. 187, no. 1, pp. 87-96, 2007.

[10] S.-I. Um, "The synthesis and properties of benzoxazole fluorescent brighteners for application to polyester fibers," Dyes and Pigments, vol. 75, no. 1, pp. 185-188, 2007.

[11] National Research Center of Egypt (NRC), "X-ray Crystallography Laboratory," 2014, http://www.xrdlab-nrc-eg.org/.

[12] R. W. W. Hooft, COLLECT, Nonius BV, Delft, The Netherlands, 1998.

[13] C. H. Görbitz, "What is the best crystal size for collection of Xray data? Refinement of the structure of glycyl-L-serine based on data from a very large crystal," Acta Crystallographica B, vol. 55, part 6, pp. 1090-1098, 1999.

[14] Z. Otwinowski and W. Minor, "Processing of X-ray diffraction data collected in oscillation mode," in Methods in Enzymology, C. W. Carter Jr. and R. M. Sweet, Eds., vol. 276 of Macromolecular Crystallography Part A, pp. 307-326, New York Academic Press, New York, NY, USA, 1997.

[15] L. Palatinus and G. Chapuis, "SUPERFLIP - a computer program for the solution of crystal structures by charge flipping in arbitrary dimensions," Journal of Applied Crystallography, vol. 40, part 4, pp. 786-790, 2007.

[16] P. W. Betteridge, J. R. Carruthers, R. I. Cooper, K. Prout, and D. J. Watkin, "CRYSTALS version 12: software for guided crystal structure analysis," Journal of Applied Crystallography, vol. 36, part 6, p. 1487, 2003.

[17] R. I. Cooper, A. L. Thompson, and D. J. Watkin, "CRYSTALS enhancements: dealing with hydrogen atoms in refinement," Journal of Applied Crystallography, vol. 43, no. 1, part 5, pp.1100$1107,2010$.

[18] K. Brandenburg, DIAMOND, Crystal Impact GbR, Bonn, Germany, 2012.

[19] “HYPERCHEM. Professional 7.51," Hypercube, Gainesville, Fla, USA.

[20] N. L. Allinger, "Conformational analysis. 130. MM2. A hydrocarbon force field utilizing V1 and V2 torsional terms," Journal of the American Chemical Society, vol. 99, no. 25, pp. 8127-8134, 1977.

[21] N. L. Allinger and Y. H. Yuh, "Quantum chemistry program exchange, Bloomington, Indiana, program no. 395," in Molecular Mechanics, U. Burkert and N. L. Allinger, Eds., vol. 177 of ACS Monograph, American Chemical Society, Washington, DC, USA, 1982.

[22] J. H. Lii and N. L. Allinger, "Molecular mechanics. The MM3 force field for hydrocarbons. 3. The van der Waals' potentials and crystal data for aliphatic and aromatic hydrocarbons," Journal of the American Chemical Society, vol. 111, no. 23, pp. 8576-8582, 1989.

[23] Q.-B. Liao, G.-H. Li, Z.-R. Zhu, and M.-G. Liu, "3-(4-chlorophenyl)-2-(diisopropylamino)-1-benzofuro[3,2-d]pyrimidin4(3H)-one," Acta Crystallographica E, vol. 64, part 1, article o13, 2008.

[24] D. E. Lynch, “2-amino-5-chloro-1,3-benzoxazole," Acta Crystallographica E, vol. 60, part 10, pp. o1715-o1716, 2004.

[25] S. Isik, Y. Köysal, M. Yavuz, M. Köksal, and H. Erdogan, “5(2-chlorobenzoyl)-1,3-benzoxazol-2(3H)-one," Acta Crystallographica E, vol. 60, part 12, pp. o2321-o2323, 2004. 
[26] D.-L. Cao, Z.-Y. Hu, J.-Q. Xue, and Y.-Q. Feng, "trans-4-[2-(1,3benzoxazol-2-yl)ethenyl]benzaldehyde," Acta Crystallographica E, vol. 63, part 6, p. o3428, 2007.

[27] D. Cremer and J. A. Pople, "A general definition of ring puckering coordinates," Journal of the American Chemical Society, vol. 97, no. 6, pp. 1354-1358, 1975.

[28] J. C. Burley, R. Gilmour, T. J. Prior, and G. M. Day, "Structural diversity in imidazolidinone organocatalysts: a synchrotron and computational study," Acta Crystallographica C, vol. 64, part 1, pp. o10-o14, 2008.

[29] O. Q. Munro and L. Mariah, "Conformational analysis: crystallographic, molecular mechanics and quantum chemical studies of $\mathrm{C}-\mathrm{H} \cdots \mathrm{O}$ hydrogen bonding in the flexible bis(nosylate) derivative of catechol," Acta Crystallographica B, vol. 60, part 5, pp. 598-608, 2004. 

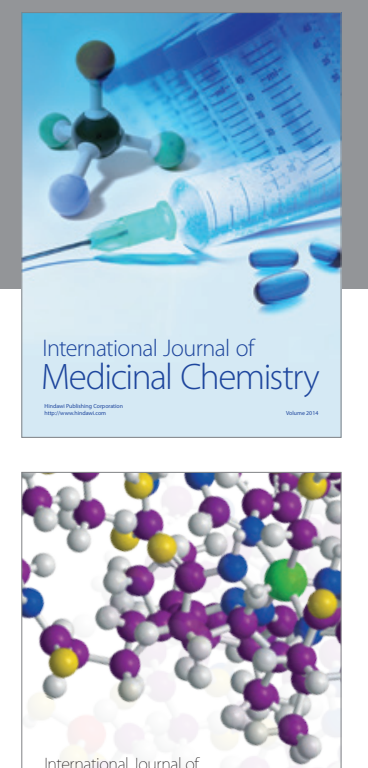

\section{Carbohydrate} Chemistry

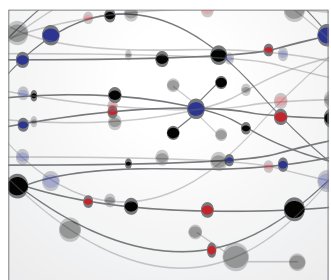

The Scientific World Journal
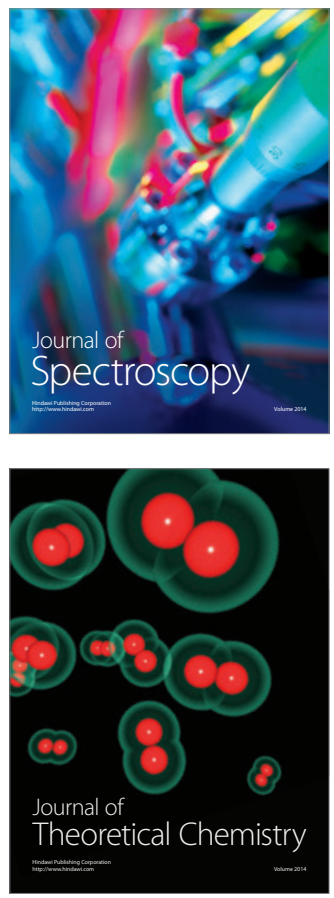
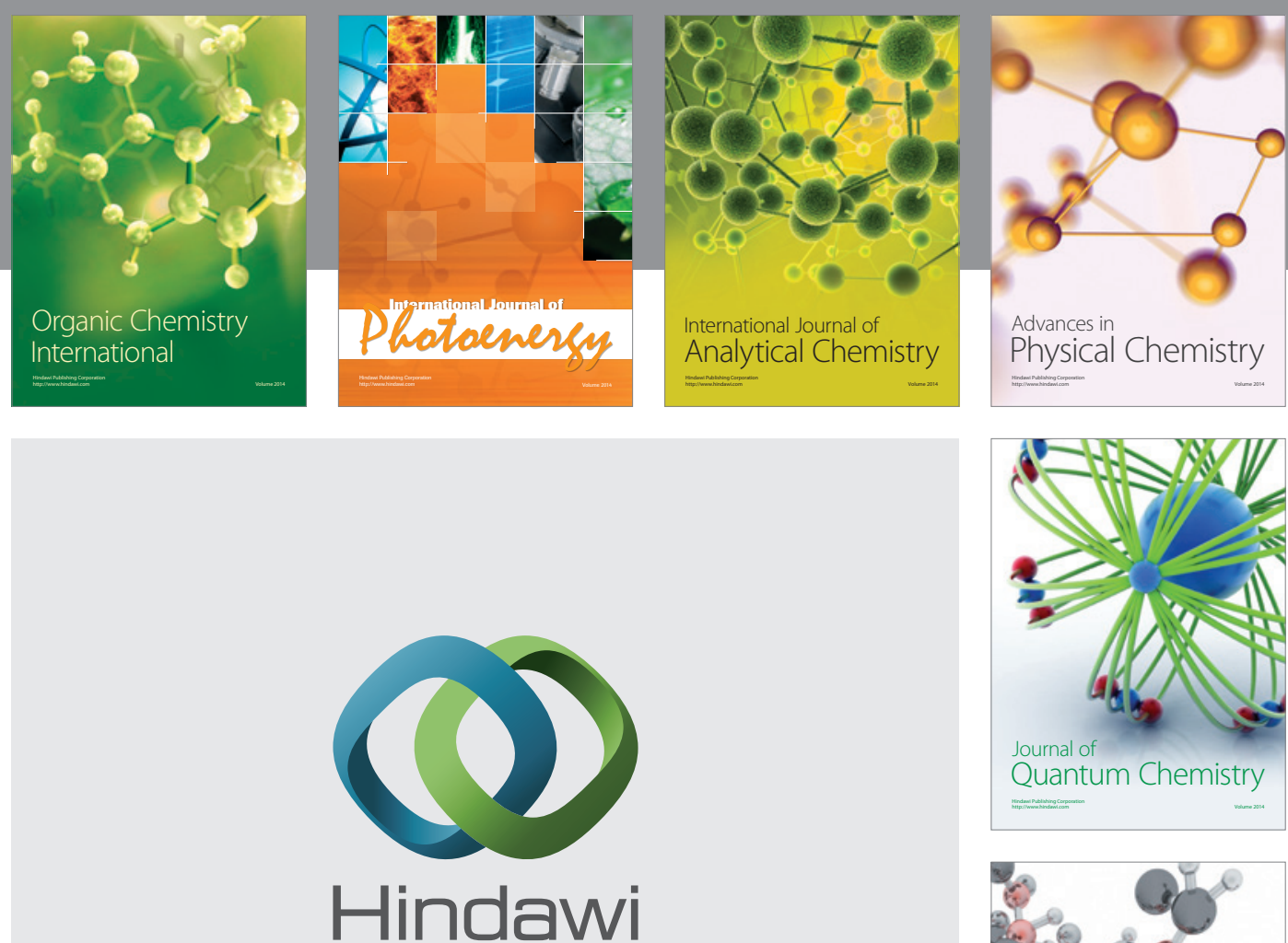

Submit your manuscripts at

http://www.hindawi.com

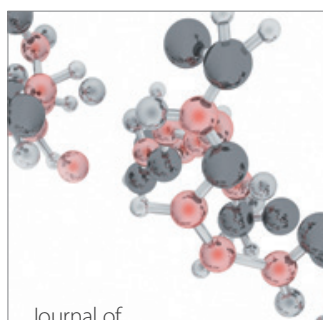

Analytical Methods

in Chemistry

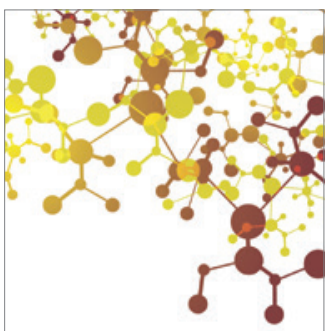

Journal of

Applied Chemistry

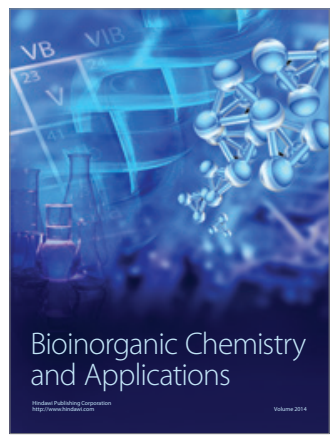

Inorganic Chemistry
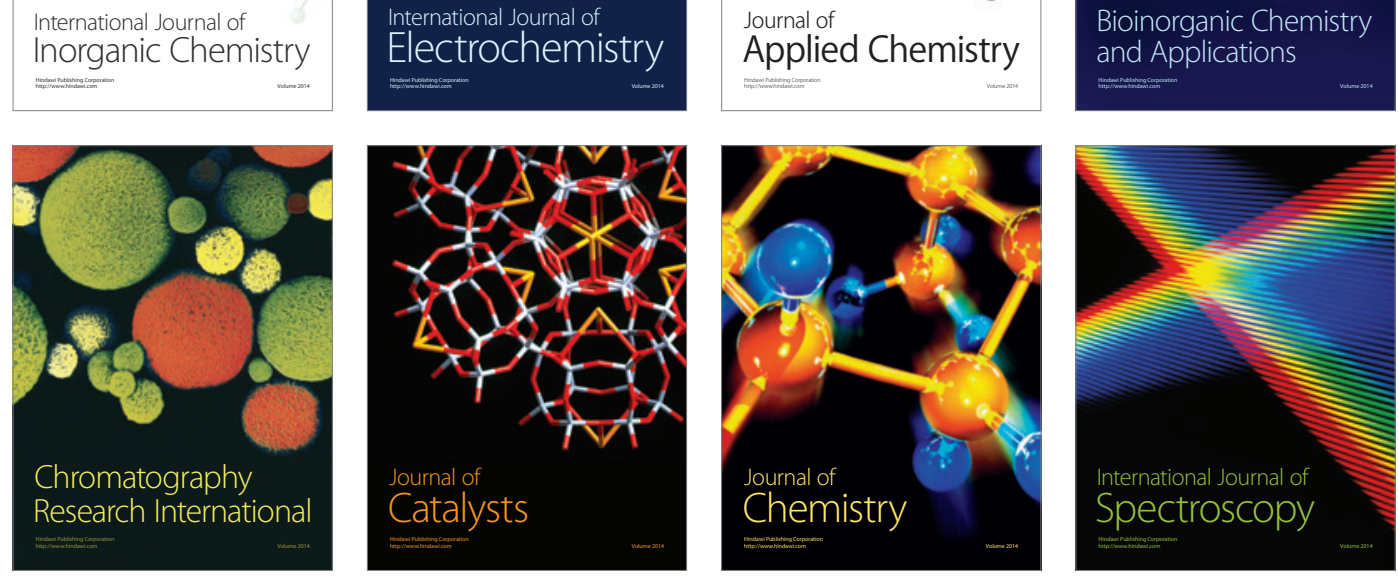